\title{
A case of hypertensive nephropathy who died of piperacillin- tazobactam induced immune hemolytic anemia which aggravated renal dysfunction: complete follow-up of serology and disease course
}

\author{
Yuanjun Wu ( $\square$ wuyuanjun199@126.com ) \\ Dongguan Maternal and Child Health Hospital \\ Yong Wu \\ Dongguan Tungwah Hospital \\ Ganping Guo \\ Dongguan Maternal and Child Health Hospital \\ Jiajun Zeng \\ Dongguan Maternal and Child Health Hospital \\ Yan Liu \\ Dongguan Tungwah Hospital \\ Yueqin Wu \\ Dongguan Tungwah Hospital
}

\section{Research Article}

Keywords: piperacillin, drug-dependent antibody, direct antiglobulin test (DAT), drug-induced immune hemolytic anaemia (DIIHA), renal dysfunction after administration

Posted Date: January 27th, 2022

DOI: https://doi.org/10.21203/rs.3.rs-1255550/v1

License: (c) (1) This work is licensed under a Creative Commons Attribution 4.0 International License. Read Full License 


\section{Abstract}

Background: Severe drug-induced immune hemolytic anaemia (DIIHA) cases leading to death are very rare. Among the reported cases of DIIHA, the serological characteristics and course of the disease are rarely described completely. Piperacillin is a semi-synthetic penicillin against pseudomonas widely used in the treatment of bacterial infections. It is one of the most common drugs that cause DIIHA.

Methods: In this study, a 79-year-old male patient with hypertensive nephropathy who developed severe hemolytic anemia during intravenous piperacillin-tazobactam anti-infective treatment due to lung infection, and worsened renal function. Serological tests included direct antiglobulin test (DAT), acid elution test, irregular red blood cell (RBC) antibody detection, and the drug-dependent antibodies associated with piperacillin or tazobactam were detected by the standard methods for the detection of drug-dependent antibodies both in the presence of soluble drug and with drug-coated RBCs. Fully described the patient's course of disease and the serological changes after stopping the administration of piperacillintazobactam.

Results: Serological tests showed that the results of DAT for anti-lgG was positive (4+) and anti-C3d was negative. The IgG piperacillin-dependent antibodies (the highest titer reached 128) were detected in the plasma incubated with O-type RBCs and $3 \mathrm{mg} / \mathrm{mL}$ piperacillin. But the plasma or the acid eluent incubated with piperacillin-coated RBCs, or the acid eluent incubated with O-type RBCs and $3 \mathrm{mg} / \mathrm{mL}$ piperacillin did not detect antibodies. The patient was diagnosed as piperacillin-induced DIIHA. Although blood transfusion and continuous renal replacement therapy were given, the patient still died of multiple organ failure 15 days after the administration of piperacillin-tazobactam was stopped.

Conclusions: DIIHA caused by piperacillin exacerbated renal damage and was an important cause of the patient's eventual death from multiple organ failure. Which has helped to deepen the understanding of DIIHA and draw lessons from it.

\section{Background}

Drug-induced immune hemolytic anemia (DIIHA) is a side effect of medication that can cause serious consequences. The annual incidence of DIIHA with obvious anemia is 1-4 per million people ${ }^{[1-3]}$. The mechanism of DIIHA is due to the immune damage to red blood cells (RBCs) caused by drug-induced antibodies (including drug-dependent antibodies and / or drug-independent antibodies) or non-immunologic protein adsorption (NIPA) ${ }^{[4-7]}$. Almost all DIIHA that is manifested as anemia is caused by drug-induced antibodies ${ }^{[4,5]}$. The NIPA mechanism can only cause a positive result of the direct antiglobulin test (DAT) and slow, difficult to observe slight hemolysis ${ }^{[6-8]}$. It has been reported that nearly 140 kinds of drugs can cause DIIHA through drug-induced antibodies, and there are 10 kinds of drugs with NIPA effect ${ }^{[5-22]}$.

Piperacillin is a semi-synthetic penicillin against pseudomonas, which belongs to the $\beta$-lactam broad-spectrum antibiotics and exerts bactericidal activity by inhibiting the synthesis of sensitive bacterial cell walls. Because some pathogenic bacteria can produce $\beta$-lactamase and are resistant to $\beta$-lactam antibiotics. Tazobactam is an irreversible competitive $\beta$-lactamase inhibitor. The combined administration of piperacillin and tazobactam can prevent the pathogens producing $\beta$-lactamase from being resistant to piperacillin, thereby expanding the antibacterial spectrum of piperacillin and improving the antibacterial effect. Piperacillin-tazobactam has been widely used for bacterial infections ${ }^{[23]}$. However, piperacillin is one of the most common drugs that cause DIIHA and can cause fatal hemolytic anemia ${ }^{[3,24]}$. Tazobactam has been confirmed to have NIPA effects and can cause mild hemolysis ${ }^{[6,7]}$. Here we report a 79-year-old male patient with hypertensive nephropathy who developed severe hemolytic anemia during intravenous piperacillin-tazobactam anti-infective treatment due to lung infection. The serological test detected piperacillin-dependent antibodies and the patient was diagnosed with piperacillin-induced DIIHA. Blood transfusion and continuous renal replacement therapy (CRRT) were given. However, the patient still died 15 days after the administration of piperacillin-tazobactam was stopped. In order to deepen the understanding of DIIHA, we fully described the patient's course of disease and the serological changes after stopping the administration of piperacillin-tazobactam, which helps to learn lessons from it.

\section{Methods}

\section{Patient Information}

A 79-year-old man was admitted to the hospital with "hypertension for more than 20 years, hypertensive nephropathy for 4 years, vomiting for 9 hours, and urinary incontinence for 5 hours". The clinical characteristics of the patient were as follows: hemoglobin ( $\mathrm{Hb}$ ) $72 \mathrm{~g} / \mathrm{L}$; alanine transaminase (ALT) 18U/L; total bilirubin (TBIL) $7.1 \mu \mathrm{mol} / \mathrm{L}$; lactate dehydrogenase (LDH) $382 \mathrm{U} / \mathrm{L}$; blood urea nitrogen (BUN) $31.47 \mathrm{mmol} / \mathrm{L}$; creatinine ( $\mathrm{Cr}$ ) $588.3 \mu \mathrm{mol} / \mathrm{L}$; glucose-6-phosphate dehydrogenase (G6PD) activity, physiological levels. Through computer tomography (CT), the diagnosis was: left frontotemporal occipital subdural hematoma, left insular hemorrhage, acute exacerbation of chronic obstructive pulmonary disease, pulmonary infection, hypertension grade 3 high-risk group, hypertension Nephropathy, chronic kidney disease stage 4, pericardial effusion. After admission, infused of leukocyte-reduced red blood cells (LRBCs) prepared from 600ml of whole blood, blood pressure control, hemostasis, erythropoietin and other supportive treatments, hemodialysis once every 2-3 days, until the 50th day after admission Cr dropped to $242.6 \mu \mathrm{mol} / \mathrm{L}$ to end hemodialysis. On the 8th day after admission, the first course of piperacillin-tazobactam anti-infective treatment was given. 
Piperacillin-tazobactam $4.5 \mathrm{~g}$ was instilled intravenously every $12 \mathrm{~h}$ for 31 consecutive days for a total of $279 \mathrm{~g}$ piperacillin-tazobactam. During and after the course of treatment, LRBCs prepared from $1400 \mathrm{ml}$ of whole blood were infused. From 49 to 53 days after admission, he was given a second course of piperacillin-tazobactam anti-infective treatment. A total of $26 \mathrm{~g}$ piperacillin-tazobactam was injected, and Cr gradually increased to $575.5 \mu \mathrm{mol} / \mathrm{L}$. On the 77 th day after admission, the third course of piperacillin-tazobactam anti-infective treatment was started. During the period, $\mathrm{Cr}$ increased to $611.8 \mu \mathrm{mol} / \mathrm{L}$ and a total of $26 \mathrm{~h}$ CRRT was given twice. On the 7th day of the third course of treatment with piperacillin-tazobactam, $\mathrm{Hb}$ dropped to a minimum of $31 \mathrm{~g} / \mathrm{L}$. Because it was suspected to be related to the treatment of piperacillin-tazobactam, the administration of piperacillin-tazobactam was stopped on the 83rd day after admission. In the third course of treatment, a total of $63 \mathrm{~g}$ piperacillin-tazobactam was injected. During the third course of treatment with piperacillin-tazobactam and within 10 days after the course of treatment, LRBCs prepared from $3200 \mathrm{ml}$ of whole blood and virus-inactivated fresh frozen plasma $1050 \mathrm{ml}$ were infused. The patient had no bleeding during hospitalization, and $\mathrm{Hb}$ was $66 \mathrm{~g} / \mathrm{L}$ after the last blood transfusion. The patient died of multiple organ failure on the $97 \mathrm{th}$ day of admission (15 days after the administration of piperacillin-tazobactam was stopped). The dynamics of Hb, ALT, LDH, TBIL, BUN, Cr, and piperacillin-tazobactam administration are shown in Figure 1.

\section{DAT and acid elution test}

The ethylene diamine tetraacetic acid (EDTA) anticoagulated peripheral blood samples were collected on days 2, 1, 0 before stopping piperacillintazobactam administration and on days 1, 2, 3, 5, 6, 9, 10, 11, 12 after stopping piperacillin-tazobactam administration, and DAT testing was performed using anti-IgG with a Coombs card (Diagnostic Grifols, S.A.) and monospecific anti-C3d (Shanghai Blood Biomedical Co., Ltd., Shanghai, China) with tube method. The acid elution test was also conducted using these RBC samples which washed 4 times with physiological saline.

\section{Irregular RBC antibody detection}

Plasma and acid eluent prepared from the EDTA anticoagulated blood samples, which were collected on days 2, 1, 0 before stopping piperacillintazobactam administration and on days $1,2,3,5,6,9,10,11,12$ after stopping piperacillin-tazobactam administration, were incubated with the antibody screening reagent red blood cells (RBCs) for antibody screening test at $37^{\circ} \mathrm{C}$ for $30 \mathrm{~min}$. The reaction mixture was centrifuged to observe hemolysis and agglutination after equilibrated at room temperature $\left(22-25^{\circ} \mathrm{C}\right)$. Then, the RBCs were washed once with physiological saline and re-suspended to a solution with a concentration of $1 \%$, and subjected to an antiglobulin test with a Coombs card (Diagnostic Grifols, Barcelona, Spain).

\section{Detection of drug-dependent antibodies in the presence of a drug solution}

The drug-dependent antibodies were tested in the presence of soluble drug following the methods of the previous reports ${ }^{[25,26]}$. Briefly, 100 $\mu \mathrm{L}$ of $3 \mathrm{mg} / \mathrm{mL}$ piperacillin solution and $1 \mathrm{mg} / \mathrm{mL}$ tazobactam solution was each incubated with $50 \mu \mathrm{L}$ of $5 \%$ O-type washed red blood cells (WRBCs, DAT result was negative and without drug treatment) and $100 \mu \mathrm{L}$ of plasma (collected on days 2 before stopping piperacillin-tazobactam administration and on days 3 after stopping piperacillin-tazobactam administration) or acid eluent at $37^{\circ} \mathrm{C}$ for $1 \mathrm{~h}$. Centrifugation was then performed to observe hemolysis and agglutination, followed by DAT with a Coombs card. AB type healthy human plasma (antibody screening test result was negative) was used instead of the patient's plasma or acid eluent囚and phosphate buffer solution (PBS) with pH 7.2 (solvent for preparing drug solutions) was used instead of the drug solutions as negative control.

\section{Detection of drug-dependent antibodies using drug-coated RBCs}

In a previous study ${ }^{[26]}$, piperacillin may be more suitable for coating RBCs under high $\mathrm{pH}$ and room temperature conditions. According to the materials available in the laboratory, we used PBS with pH 7.2 and pH 9.0 to prepare piperacillin solution and tazobactam solution with all a concentration of $40 \mathrm{mg} / \mathrm{ml}$. These drug solutions was each incubated with O-type WRBCs (DAT result was negative) at room temperature and $37^{\circ} \mathrm{C}$ for 1 hour individually, to prepared drug-coated RBCs. And then, $50 \mu \mathrm{L}$ of drug-coated RBCs were incubated with $100 \mu \mathrm{L}$ of plasma, or 100 $\mu \mathrm{L}$ of acid eluent at $37^{\circ} \mathrm{C}$ for $1 \mathrm{~h}$. Centrifugation was then performed to observe hemolysis and agglutination, followed by DAT with a Coombs card to detect piperacillin-dependent antibodies or tazobactam-dependent antibodies in the plasma or acid eluent.

\section{Detection the titers of drug-dependent antibody}

The piperacillin-dependent antibodies were detected in plasma incubated with $3 \mathrm{mg} / \mathrm{mL}$ piperacillin solution and O-type WRBCs. Therefore, the plasma samples collected on days $2,1,0$ before stopping piperacillin-tazobactam administration and on days 1, 2, 3, 5, 6, 9, 10, 11, 12 after 
stopping piperacillin-tazobactam administration were diluted by physiological saline, and then the plasma samples of different dilutions were incubated with $3 \mathrm{mg} / \mathrm{mL}$ piperacillin solution and O-type WRBCs at $37^{\circ} \mathrm{C}$ for $1 \mathrm{~h}$, followed by DAT with a Coombs card, to detect the titers of piperacillin-dependent antibodies.

\section{Results}

\section{Results of DAT and irregular RBC antibody screening}

The DAT for anti-IgG results of blood samples collected on days 2, 1, 0 before stopping piperacillin-tazobactam administration were strongly positive (4+). After stopping the administration of piperacillin-tazobactam, the DAT for anti-lgG results gradually weakened囚and turned negative until 12 days after the administration of piperacillin-tazobactam was stopped. The DAT for anti-C3d results of all blood samples were negative. Table 1 shows the detailed results of DAT. Plasma samples collected on days 2, 1, 0 before stopping piperacillin-tazobactam administration incubated with the antibody screening reagent RBCs for antibody screening test at $37^{\circ} \mathrm{C}$ for 30 min, the results of the antiglobulin tests with a Coombs card were all weak positive. But the plasma samples collected after stopping piperacillin-tazobactam administration or the all of acid eluent incubated with the antibody screening reagent RBCs at $37^{\circ} \mathrm{C}$ for $30 \mathrm{~min}$, the results of the antiglobulin tests with a Coombs card were all negative. Which prompt that the irregular RBC antibody was negative, and the plasma samples collected on days $2,1,0$ before stopping piperacillin-tazobactam administration incubated with the antibody screening reagent RBCs at $37^{\circ} \mathrm{C}$ for 30 min, the result of the antiglobulin tests were weak positive, which should be due to the presence of piperacillin in the patient's plasma, and the piperacillin-dependent antibodies have weakly agglutinated with the RBCs.

\section{Results of drug-dependent antibody testing}

Plasma samples of the patient collected on days 2 before and days 3 after stopping piperacillin-tazobactam administration was each incubated with $5 \%$ O-type WRBCs and $3 \mathrm{mg} / \mathrm{mL}$ piperacillin solution at $37^{\circ} \mathrm{C}$ for $1 \mathrm{~h}$, observed after centrifugation, and there were no hemolysis or agglutination, but the anti-globulin tests performed with a monospecific anti-lgG Coombs card were both positive (4+). Plasma sample of the patient collected on days 2 before stopping piperacillin-tazobactam administration was incubated with 5\% 0-type WRBCs, or piperacillin-coated RBCs, or tazobactam-coated RBCs at $37^{\circ} \mathrm{C}$ for $1 \mathrm{~h}$, observed after centrifugation, and there were no hemolysis or agglutination, but the antiglobulin tests performed with a monospecific anti-lgG Coombs card were all positive (3+). However, plasma sample of the patient collected on days 3 after stopping piperacillin-tazobactam administration was incubated with 5\% 0-type WRBCs, or piperacillin-coated RBCs, or tazobactamcoated RBCs at $37^{\circ} \mathrm{C}$ for $1 \mathrm{~h}$, observed after centrifugation, and there were no hemolysis or agglutination, and the anti-globulin tests performed with a monospecific anti-IgG Coombs card were all negative. Therefore, it is judged that there were IgG piperacillin-dependent antibodies that can only be detected in piperacillin solution and do not react with piperacillin-coated RBCs in the patient's plasma. Plasma sample collected on days 2 before stopping piperacillin-tazobactam administration was incubated with O-type WRBCs, or piperacillin-coated RBCs, or tazobactam-coated RBCs at $37^{\circ} \mathrm{C}$ for $1 \mathrm{~h}$, the results of the anti-globulin tests were positive because of the presence of piperacillin in the patient's plasma. No tazobactam-dependent antibody was detected in the plasma samples and acid eluent collected before and after the patient stopped the administration of piperacillin-tazobactam, and no piperacillin-dependent antibody was detected in the acid eluent of the patient. The detailed results of drug-dependent antibody detection in patient's plasma and acid eluent are shown in Table 2 . The titers of IgG piperacillin-dependent antibodies in plasma samples collected 2 days before to 12 days after the patient stopped taking piperacillin-tazobactam are shown in Table 1.

\section{Discussions}

Piperacillin is the most immunogenic drug ${ }^{[27,28]}$ and the most common antibacterial drug reported to cause DIIHA. There have been dozens of cases of severe DIIHA caused by piperacillin, including deaths. These cases are all caused by the immune complex mechanism, that is, the antibodies induced by piperacillin ${ }^{[3,24,29-35]}$. Drug-induced antibodies include drug-dependent antibodies and drug-independent antibodies. Drugdependent antibodies must react in vivo or in vitro only in the presence of related drugs or their metabolites. Drug-independent antibodies are similar to warm autoantibodies against RBCs, and can react in vivo or in vitro in the absence of related drugs that induce antibodies and their metabolites ${ }^{[2,5]}$. The vast majority of DIIHA with obvious hemolysis is caused by drug-dependent antibodies, which are manifested as immune hemolytic anemia with a clear time correlation with the relevant administration. After the administration is stopped, the hemolysis is relieved and gradually stopped. It is very difficult to distinguish between drug-independent antibodies and warm autoantibodies against RBCs and to diagnose DIIHA caused by drug-independent antibodies. The duration of immune hemolytic anemia caused by drug-independent antibodies after stopping the administration of related drugs is not clear ${ }^{[36,37]}$. We previously reported a case of DIIHA caused by oral administration of cimetidine. Both cimetidine-coated RBCs and cimetidine solution were used to detect cimetidine-dependent antibodies with the highest titer of 4096 . Hemolysis was quickly relieved after cimetidine administration was stopped. However, drug-independent non-specific antibodies were detected 13 days after the cimetidine administration was stopped, and the titer gradually increased, reaching a peak value of 32 on 34 days after the cimetidine administration was stopped. With the increase in the titer of drug-independent non-specific antibodies, by detecting the lifespan of RBCs, it was

Page $4 / 11$ 
detected that hemolysis accelerated again after the early remission after stopping the administration of cimetidine, which resulted in immune hemolytic anemia caused by the drug-independent non-specific antibodies continued until 41 days after the cimetidine administration was stopped. However, until 82 days after the administration of cimetidine was stopped, the result of DAT for anti-lgG was still strongly positive, the titer of cimetidine-dependent antibodies was 2048 , and the titer of drug-independent non-specific antibodies was 8 . But at this time, the patient's $\mathrm{Hb}$ has returned to normal levels ${ }^{[38]}$.

Diagnosis of DIIHA includes the positive results of DAT for anti-IgG and/or for anti-C3d, detection of drug-induced antibodies, including drugdependent antibodies, and/or drug-independent antibodies which non-existent before administration, but induced by the drug after administration, and it can be traced back to the time-dependent immune hemolysis ${ }^{[5,25]}$. In the reported cases of DIIHA caused by piperacillin diagnosed by standard serological tests, almost all of them have detected positive results of DAT for anti-IgG and no blood group antigenspecific piperacillin-dependent antibodies ${ }^{[3,24,29-35,39,40]}$. Most of these cases show acute intravascular hemolysis because piperacillin-dependent antibodies can activate complement ${ }^{[3,24,29-35]}$.

There are many reasons for the positive DAT result ${ }^{[36]}$, but in DIIHA, the positive result of DAT for anti-C3d may reflect that the drug-induced antibodies can activate complement and cause acute intravascular hemolysis. Among the 8 cases of severe DIIHA caused by piperacillin reported by Mayer et al. ${ }^{[29]}$, the lowest value of $\mathrm{Hb}$ was $7.7 \mathrm{~g} / \mathrm{dL}$ in one case with negative DAT for anti-C3d result, and the lowest $\mathrm{Hb}$ values of other 7 patients with positive DAT for anti-C3d results were all lower than $7.7 \mathrm{~g} / \mathrm{dL}$, it suggests that DAT for anti-C3d may be related to the severity of DIIHA. In the reported cases of DIIHA caused by piperacillin, drug-independent antibodies induced by piperacillin are rarely detected. In a prospective study of the risk of DIIHA caused by piperacillin in patients with cystic fibrosis and anti-pseudomonas infection treated with piperacillin, 1 patient was receiving piperacillin-tazobactam combination, during the treatment, a mild immunohemolytic anemia occurred, and this patient was detected Rhe-specific autoantibodies. But after dialysis to remove piperacillin in the sample, the antibodies could not be detected, and the addition of piperacillin or its metabolite (urine during piperacillin treatment), the autoantibodies with Rhe specificity can be detected. This study shows that the antibodies are also piperacillin-dependent antibodies ${ }^{[3]}$.

Methods to detect drug-dependent antibodies include detection of drug-coated RBCs and detection in the presence of soluble drug ${ }^{[5,25]}$. Since the mechanism of drug-dependent antibodies production may be different, different drug-dependent antibodies may be suitable for detection by different methods ${ }^{[9]}$. The mechanism of DIIHA caused by penicillin is due to the immune damage of penicillin-dependent antibodies produced by the body to RBCs coated with penicillin. Patients with DIIHA caused by penicillin are suitable for penicillin-coated RBCs to detect penicillindependent antibodies ${ }^{[25,26]}$. Although piperacillin is a semi-synthetic penicillin, piperacillin-dependent antibodies have different serological characteristics from penicillin-dependent antibodies. A serological study on piperacillin-dependent antibodies by the American Red Cross Blood Service in Southern California 13 years ago ${ }^{[26]}$ showed: The piperacillin-coated RBCs were prepared by incubating 40mg/ml piperacillin solution (prepared with pH 9.8 barbital buffer solution) with 0-type RBCs at 10:1 at room temperature for 1 hour. Then the plasma of 100 blood donors was each incubated with the piperacillin-coated RBCs at $37^{\circ} \mathrm{C}$ for 1 hour, and IgM piperacillin-dependent antibodies were detected in the plasma of 91 blood donors. And these antibodies can be completely inhibited by $10 \mathrm{mg} / \mathrm{ml}$ piperacillin. It was believed that the possible reason for the detection of IgM piperacillin-dependent antibodies in a high rate of blood donors was exposure to $\beta$-lactam or closely related chemicals in the environment (for example, it may be added to cattle feed or present in milk). However, 6 patients with DIIHA caused by piperacillin observed during the same period could only detect piperacillin-dependent antibodies by incubating the patient's plasma, piperacillin solution and RBCs, but the piperacillin-dependent antibodies could not be detected by the piperacillin-coated RBCs. It is suggested that the piperacillin-dependent antibody produced by exposure to piperacillin or related chemicals in the environment and the piperacillin-dependent antibody induced by piperacillin administration have different serological characteristics. The clinical significance of piperacillin-dependent antibodies produced by exposure to piperacillin or related chemicals in the environment is unclear.

According to the methods of the previous reports ${ }^{[25]}, 1 \mathrm{mg} / \mathrm{ml}$ is the standard drug concentration used to detect drug-dependent antibodies in the presence of soluble drug. However, a serological study by Leger et al ${ }^{[26]}$. on piperacillin-dependent antibodies showed that piperacillin solutions with a concentration of $1-10 \mathrm{mg} / \mathrm{ml}$ can detect piperacillin-dependent antibodies in patients with DIIHA caused by piperacillin, but when there is a high concentration of piperacillin, piperacillin-dependent antibody response will be stronger. Therefore, we used $3 \mathrm{mg} / \mathrm{ml}$ piperacillin solution to detect piperacillin-dependent antibodies, and $1 \mathrm{mg} / \mathrm{ml}$ tazobactam solution to detect the presence of tazobactam-related antibodies.

In this case, the serological test results showed that DAT for anti-IgG was strongly positive (4+) and for anti-C3d was negative. There were IgG piperacillin-dependent antibodies in the plasma detected after incubation with piperacillin solution and RBCs at $37^{\circ} \mathrm{C}$, but no reaction with piperacillin-coated RBCs. The clinical manifestations were hemolytic anemia and aggravation of renal dysfunction with a clear time correlation with piperacillin administration, which can be diagnosed as DIIHA caused by piperacillin. Although the results of continuous monitoring of DAT for anti-C3d were negative after the diagnosis was confirmed, the patient's hemolysis was severe (the lowest value of $\mathrm{Hb}$ detected was $31 \mathrm{~g} / \mathrm{L}$ ), which suggests that severe DIIHA can occur in patients with negative result of DAT for anti-C3d. 
The patient in this study, $\mathrm{Hb} 72 \mathrm{~g} / \mathrm{L}$ before administration of piperacillin-tazobactam, three courses within 3 months, total intravenous administration of piperacillin-tazobactam $368 \mathrm{~g}$, during which a total of LRBCs prepared from $5200 \mathrm{ml}$ of whole blood were infused, and $\mathrm{Hb} 66 \mathrm{~g} / \mathrm{L}$ after the last infusion of LRBCs. The patient had severe hypertensive renal impairment. During the first course of piperacillin-tazobactam administration, because of multiple times CRRT, hemodialysis, blood transfusion and other treatments were given, and the strength of the piperacillin-dependent antibodies may be low, he did not show obvious clinical characteristics of DIIHA. Significantly aggravated renal damage occurred after the CRRT was stopped during the second and third courses of piperacillin-tazobactam administration, while severe hemolytic anemia occurred in the third course of piperacillin-tazobactam and within a few days after the end of third course, possibly because the patient repeated immunization with piperacillin increased the strength of piperacillin-dependent antibodies. Due to insufficient knowledge of DIIHA and lack of necessary vigilance ${ }^{[3,10]}$, when the patient experienced aggravated renal damage and severe hemolytic anemia, the administration of piperacillin-tazobactam could not be stopped in time, which led to the patient's condition deteriorated rapidly after the third course of piperacillintazobactam administration. Although the diagnosis of DIIHA due to piperacillin was confirmed by serological testing after consultation with an immunohematologist, and the administration of piperacillin-tazobactam was discontinued. However, the patient eventually died of multiple organ failure. Predisposing factors to multiple organ failure may included infection, but severe DIIHA should be a more important factor. Based on the lessons of this case and the recommendations previously reported, DIIHA caused by piperacillin has been regarded as a highly acute and life threatening event, particularly if it remains undetected in due time ${ }^{[2]}$. Any patient who develops hemolytic anemia during the administration of piperacillin should consider the possibility of DIIHA. A timely serological test to confirm the diagnosis and stop the administration of piperacillin is the most effective strategy to avoid the serious consequences of DIIHA caused by piperacillin.

\section{Conclusions}

This is a case of DIIHA caused by piperacillin with complete tracking of serological changes and disease processes, but lack of reticulocyte count and haptoglobin data, and incomplete LDH monitoring. Due to insufficient knowledge of DIIHA, the diagnosis was delayed. It is worth learning a profound lesson. DIIHA is a side effect of medication that can lead to serious consequences, even fatal. Due to the low incidence of severe DIIHA, it has not yet received the attention of clinicians, clinical pharmacists and drug manufacturers. In China, DIIHA has not yet been included in the medication risk monitoring system. It is now clear that there are nearly 140 drugs that can cause DIIHA through immune complex mechanisms (ie, drug-induced antibodies) ${ }^{[5,9-22,38]}$, but DIIHA has not been included in the list of side effects of these drugs, and there is a lack of DIIHA vigilance, the vast majority of DIIHA may be missed, misdiagnosed, delayed in diagnosis, or given improper intervention, which increases the risk of patients' administration. Incorporating DIIHA into the medication risk monitoring system and improving the awareness and vigilance of DIIHA will help avoid the serious consequences of DIIHA on patients.

\section{Abbreviations}

DIIHA, drug-induced immune haemolytic anaemia; NIPA, non-immunologic protein adsorption; RBC, red blood cell; RBCs, red blood cells; WRBCs, washed red blood cells; LRBCs, leukocyte-reduced red blood cells; DAT, direct antiglobulin test; Hb, haemoglobin; ALT: alanine transaminase; TBIL: total bilirubin; LDH, lactate dehydrogenase; BUN, blood urea nitrogen; Cr: creatinine; G6PD, Glucose-6-phosphate dehydrogenase; CT: computer tomography; PBS, phosphate buffer solution; CRRT: continuous renal replacement therapy.

\section{Declarations}

\section{Acknowledgments}

We thank the patient's family members who were involved in this study and for granting the right of publication.

\section{Authors' contributions}

(I) Collection of sample and clinical data: YW; ( () conception and design: YJW and YW; ( $)$ serological tests: YW, YJW, GPG, JJZ, YL and YQW; ( $)$ data analysis and interpretation: YJW and YW; (V) manuscript writing: YW and YJW. All authors read and approved the final manuscript.

\section{Funding}

This work was supported mainly by a grant from the Social Science and Technology Development Key Project of Dongguan City (201950715046181).

\section{Availability of data and materials}


The data set used and/or analyzed during the current study are available from the corresponding author on reasonable request.

\section{Ethics approval and consent to participate}

This study was authorized by the Ethics Committee of Dongguan Tungwah Hospital. Written informed consent to participate in this study was provided by the participants' legal guardian/next of kin.

\section{Consent for publication}

The patient's legal guardian provided informed consent for publication of this study.

\section{Competing interests}

The authors declare that they have no competing interest.

\section{References}

1. Garbe E, Andersohn F, Bronder E, Klimpel A, Thomae M, Schrezenmeier H, Hildebrandt M, Späth-Schwalbe E, Grüneisen A, Mayer B, Salama A, Kurtal H. Drug induced immune haemolytic anaemia in the Berlin Case-Control Surveillance Study. Br J Haematol. 2011; 154(5): 644-53. doi: 10.1111/j.1365-2141.2011.08784.x.

2. Mayer B, Bartolmäs T, Yürek S, Salama A. Variability of Findings in Drug-Induced Immune Haemolytic Anaemia: Experience over 20 Years in a Single Centre. Transfus Med Hemother. 2015; 42(5): 333-9. doi: 10.1159/000440673.

3. Roehmel J, Specht P, Staab D, Schwarz C, Salama A, Mayer B. Risk of piperacillin-induced hemolytic anemia in patients with cystic fibrosis and antipseudomonal treatment: a prospective observational study. Transfusion. 2019; 59(12): 3746-3754. doi: 10.1111/trf.15591.

4. Garratty G. Immune hemolytic anemia associated with drug therapy. Blood Rev. 2010; 24(4-5):143-150.

5. Arndt PA. Drug-induced immune hemolytic anemia: the last 30 years of changes. Immunohematology. 2014; 30(2): 44-54.

6. Garratty G, Arndt PA. Positive direct antiglobulin tests and haemolytic anaemia following therapy with beta-Lactamase inhibitor containing drugs may be associated with nonimmunologic adsorption of protein onto red blood cells. Br J Haematol. 1998; 100(4): 777-783.

7. Arndt PA, Leger RM, Garratty G. Positive direct antiglobulin tests and haemolytic anaemia following therapy with the beta-lactamase inhibitor, tazobactam, may also be associated with non-immunologic adsorption of protein onto red blood cells. Vox Sang. 2003; 85(1): 53.

8. Arndt PA, Garratty G, Isaak E, et al. Positive Direct and Indirect Antiglobulin Tests Associated With Oxaliplatin Can Be Due to Drug Antibody and/or Drug-Induced Nonimmunologic Protein Adsorption. Transfusion. 2009; 49:711-8.

9. Garratty G, Arndt PA. Drugs that have been shown to cause drug-induced immune hemolytic anemia or positive direct antiglobulin tests: some interesting findings since 2007. Immunohematology. 2014; 30(2): 66-79.

10. Wu Y, Wu Y, Ji Y, Liang J, He Z, Liu Y, Tang L and Guo G. Case Report: Drug-Induced Immune Haemolytic Anaemia Caused by CefoperazoneTazobactam/ Sulbactam Combination Therapy. Front. Med. (2021) 8: 697192. doi: 10.3389/fmed.2021.697192

11. Wu Y, Wu Y, Ji Y, Liu Y, Wu D, Liang J, Guo G and Chen B. Case Report: Oral Cimetidine Administration Causes Drug-Induced Immune Hemolytic Anemia by Eliciting the Production of Cimetidine-Dependent Antibodies and Drug-Independent Non-specific Antibodies. Front. Med. (2021) 8: 723167. doi: 10.3389/fmed.2021.723167

12. Kurth F, Lingscheid T, Steiner F, Stegemann MS, Bélard S, Menner N, Pongratz P, Kim J, von Bernuth H, Mayer B, Damm G, Seehofer D, Salama A, Suttorp N, Zoller T. Hemolysis after Oral Artemisinin Combination Therapy for Uncomplicated Plasmodium falciparum Malaria. Emerg Infect Dis. 2016; 22(8): 1381-6. doi: 10.3201/eid2208.151905.

13. Quintanilla-Bordás C, Castro-Izaguirre E, Carcelén-Gadea M, et al. The first reported case of drug-induced hemolytic anemia caused by dimethyl fumarate in a patient with multiple sclerosis. Transfusion. 2019; 59(5): 1648-1650.

14. Chan M, Silverstein WK, Nikonova A, et al. Bendamustine-induced immune hemolytic anemia: a case report and systematic review of the literature. Blood Adv. 2020; 4(8): 1756-1759.

15. Burgos Pratx L, Santoro D, Coca Mogro B, et al. Etoricoxib-induced immune hemolytic anemia: first case presenting acute kidney failure. Transfusion. 2019; 59(5): 1657-1660.

16. Lin KS, Win S, Nyein PP. Drug-induced immune hemolytic anemia because of efavirenz: a case report. AIDS. 2020; 34(2): 326-328.

17. Nguyen TN, Maenulein E, Fihman V, Vinatier I, Klaren JM. Serologic characteristics of oxaliplatin antibodies in 15 patients with drug-induced immune hemolytic anemia. Transfusion. 2021; doi: 10.1111/trf.16360. 
18. Fukuda M, Nabeta M, Oya S, Takasu O. Severe drug-induced immune hemolytic anemia due to cefmetazole: A case report. Int J Clin Pharmacol Ther. 2021; doi: 10.5414/CP204095.

19. Afra F, Mehri M, Namazi S. Bosentan-induced immune hemolytic anemia in 17 years old man. A case report. Daru. 2021; 29(1): 211-215. doi: 10.1007/s40199-020-00386-1.

20. Okumoto J, Sakamoto S, Masuda T, Yamaguchi K, Horimasu Y, Miyamoto S, Nakashima T, Iwamoto H, Fukushima N, Fujitaka K, Hamada H, Hattori N. Alectinib-induced Immune Hemolytic Anemia in a Patient with Lung Adenocarcinoma. Intern Med. 2021; 60(4): 611-615. doi: 10.2169/internalmedicine.4241-19.

21. Al-Ansari RY, Khuraim AA, Abdalla L, Hamid H, Zakary NY. Remsima (a Tumor Necrosis Factor (TNF) -alpha Inhibitor) induced hemolysis in a patient with Crohn's disease - Case report. Ann Med Surg (Lond). 2021; 69:102768. doi: 10.1016/j.amsu.2021.102768.

22. Shen Y, Yu F, Ge H, Shao K, Zhou Y, Ye B, Shen Y, Wu D. First Report of Severe Autoimmune Hemolytic Anemia During Eltrombopag Therapy in Waldenstrom Macroglobulinemia-Associated Thrombocytopenia. Onco Targets Ther. 2021; 14: 5027-5033. doi: 10.2147/OTT.S333189.

23. Schoonover LL, Occhipinti DJ, Rodvold KA, Danziger LH. Piperacillin/tazobactam: a new beta-lactam/beta-lactamase inhibitor combination. Ann Pharmacother. 1995; 29(5): 501-14. doi: 10.1177/106002809502900510.

24. Marik PE, Parekh P. Life-threatening piperacillin-induced immune haemolysis in a patient with cystic fibrosis. BMJ Case Rep. 2013; 2013:bcr2012007801. doi: 10.1136/bcr-2012-007801.

25. Leger RM, Arndt PA, Garratty G. How we investigate drug-induced immune hemolytic anemia. Immunohematology. 2014; 30(2): 85-94.

26. Leger RM, Arndt PA, Garratty G. Serological studies of piperacillin antibodies. Transfusion. 2008; 48(11): 2429-34. doi: 10.1111/j.15372995.2008.01852.x.

27. Amali MO, Sullivan A, Jenkins RE, Farrell J, Meng X, Faulkner L, Whitaker P, Peckham D, Park BK, Naisbitt DJ. Detection of drug-responsive B lymphocytes and antidrug IgG in patients with beta-lactam hypersensitivity. Allergy. 2017; 72(6): 896-907. doi: 10.1111/all.13087.

28. Sullivan A, Wang E, Farrell J, Whitaker P, Faulkner L, Peckham D, Park BK, Naisbitt DJ. $\beta$-Lactam hypersensitivity involves expansion of circulating and skin-resident T(H)22 cells. J Allergy Clin Immunol. 2018; 141(1): 235-249.e8. doi: 10.1016/j.jaci.2017.01.020.

29. Mayer B, Yürek S, Salama A. Piperacillin-induced immune hemolysis: new cases and a concise review of the literature. Transfusion. 2010; 50(5): 1135-8. doi: 10.1111/j.1537-2995.2009.02544.x.

30. Lohiya GS, Tan-Figueroa L, Krishna V. Piperacillin-induced immune hemolysis presenting with tachycardia and cardiac arrest. Case Rep Med. 2011; 2011: 816497. doi: 10.1155/2011/816497.

31. Kunzmann S, Thomas W, Mayer B, Kuhn S, Hebestreit H. Immune-mediated severe hemolytic crisis with a hemoglobin level of $1.6 \mathrm{~g} / \mathrm{dl}$ caused by anti-piperacillin antibodies in a patient with cystic fibrosis. Infection. 2010; 38(2): 131-4. doi: 10.1007/s15010-0099227-8.

32. Chavez A, Mian A, Scurlock AM, Blackall D, Com G. Antibiotic hypersensitivity in CF: drug-induced life-threatening hemolytic anemia in a pediatric patient. J Cyst Fibros. 2010; 9(6): 433-8. doi: 10.1016/j.jcf.2010.08.010.

33. Arndt PA, Garratty G, Hill J, Kasper M, Chandrasekaran V. Two cases of immune haemolytic anaemia, associated with anti-piperacillin, detected by the 'immune complex' method. Vox Sang. 2002; 83(3): 273-8. doi: 10.1046/j.1423-0410.2002.00188.x.

34. Wang Q, He Z, Wu X, Wei Y, Huang J. Hematologic adverse effects induced by piperacillin-tazobactam: a systematic review of case reports. Int J Clin Pharm. 2020; 42(4): 1026-1035. doi: 10.1007/s11096-020-01071-8.

35. Nagao B, Yuan S, Bon Homme M. Sudden onset of severe anemia in a patient with cystic fibrosis. Clin Chem. 2012; 58(9): 1286-9. doi: 10.1373/clinchem.2011.167213.

36. Parker V, Tormey CA. The Direct Antiglobulin Test: Indications, Interpretation, and Pitfalls. Arch Pathol Lab Med. 2017; 141(2): 305-310. doi: 10.5858/arpa.2015-0444-RS.

37. Salama A. Clinically and/or Serologically Misleading Findings Surrounding Immune Haemolytic Anaemias. Transfus Med Hemother. 2015; 42(5): 311-5. doi: 10.1159/000438960.

38. Wu Y, Wu Y, Ji Y, Liu Y, Wu D, Liang J, Guo G and Chen B. Case Report: Oral Cimetidine Administration Causes Drug-Induced Immune Hemolytic Anemia by Eliciting the Production of Cimetidine-Dependent Antibodies and Drug-Independent Non-specific Antibodies. Front. Med. (2021) 8: 723167. doi: 10.3389/fmed.2021.723167

39. Thickett KM, Wildman MJ, Fegan CD, Stableforth DE. Haemolytic anaemia following treatment with piperacillin in a patient with cystic fibrosis. J Antimicrob Chemother. 1999; 43(3): 435-6. doi: 10.1093/jac/43.3.435.

40. Bandara M, Seder DB, Garratty G, Leger RM, Zuckerman JB. Piperacillin-induced immune hemolytic anemia in an adult with cystic fibrosis. Case Rep Med. 2010; 2010: 161454. doi: 10.1155/2010/161454.

\section{Tables}


Results of DAT and the titers of piperacillin-dependent antibodies

\begin{tabular}{|c|c|c|c|}
\hline \multirow[t]{2}{*}{ After stopping the administration of piperacillin-tazobactam (day) } & \multicolumn{2}{|c|}{ Direct antiglobulin test } & \multirow[t]{2}{*}{ Titers of piperacillin-dependent antibodies } \\
\hline & anti-IgG & anti-C3d & \\
\hline-2 & $4+$ & negative & 64 \\
\hline 0 & $4+$ & negative & no detection \\
\hline 1 & $3+$ & negative & no detection \\
\hline 2 & $3+$ & negative & 64 \\
\hline 3 & $2+$ & negative & no detection \\
\hline 5 & $2+$ & negative & no detection \\
\hline 6 & $1+$ & negative & 128 \\
\hline 9 & $1+$ & negative & 128 \\
\hline 10 & weak positive & negative & 64 \\
\hline 11 & weak positive & negative & 64 \\
\hline 12 & negative & negative & 64 \\
\hline
\end{tabular}

Table 2

Test results of drug-dependent antibodies in blood samples collected 2 days before and 3 days after stopping the administration of piperacillintazobactam 
NO. Reactive materials

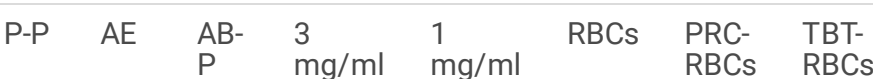

Incubation

conditions
Observe

Agglutination Hemolysis 2 days 3 days before after stopping stopping

(ul) $\quad$ PRC TBT

\begin{tabular}{|c|c|c|c|c|c|c|c|c|c|c|c|c|c|}
\hline & $(\mu \mathrm{l})$ & $(\mu \mathrm{l})$ & $(\mu \mathrm{l})$ & $(\mu \mathrm{l})$ & $(\mu l)$ & $(\mu \mathrm{l})$ & $(\mu \mathrm{l})$ & $(\mu \mathrm{l})$ & & & & & \\
\hline 1 & 100 & I & / & 100 & I & 50 & I & I & $37^{\circ} \mathrm{C}, 1 \mathrm{~h}$ & - & - & $4+$ & $4+$ \\
\hline 2 & 100 & I & I & I & 100 & 50 & I & I & $37^{\circ} \mathrm{C}, 1 \mathrm{~h}$ & - & - & - & - \\
\hline 3 & I & 100 & I & 100 & I & 50 & I & I & $37^{\circ} \mathrm{C}, 1 \mathrm{~h}$ & - & - & - & - \\
\hline 4 & I & 100 & / & / & 100 & 50 & / & / & $37^{\circ} \mathrm{C}, 1 \mathrm{~h}$ & - & - & - & - \\
\hline 5 & 100 & / & / & / & / & 50 & / & / & $37^{\circ} \mathrm{C}, 1 \mathrm{~h}$ & - & - & $3+\triangle$ & - \\
\hline 6 & 100 & / & / & / & / & I & 50 & / & $37^{\circ} \mathrm{C}, 1 \mathrm{~h}$ & - & - & $3+\triangle$ & - \\
\hline 7 & 100 & I & / & I & I & / & / & 50 & $37^{\circ} \mathrm{C}, 1 \mathrm{~h}$ & - & - & $3+\triangle$ & - \\
\hline 8 & I & 100 & / & / & / & 50 & / & / & $37^{\circ} \mathrm{C}, 1 \mathrm{~h}$ & - & - & - & - \\
\hline 9 & / & 100 & / & / & / & / & 50 & / & $37^{\circ} \mathrm{C}, 1 \mathrm{~h}$ & - & - & - & - \\
\hline 10 & I & 100 & / & / & / & / & / & 50 & $37^{\circ} \mathrm{C}, 1 \mathrm{~h}$ & - & - & - & - \\
\hline 11 & I & / & 100 & 100 & I & 50 & / & / & $37^{\circ} \mathrm{C}, 1 \mathrm{~h}$ & - & - & - & - \\
\hline 12 & I & I & 100 & I & I & 50 & I & I & $37^{\circ} \mathrm{C}, 1 \mathrm{~h}$ & - & - & - & - \\
\hline 13 & / & / & 100 & / & / & / & 50 & / & $37^{\circ} \mathrm{C}, 1 \mathrm{~h}$ & - & - & - & - \\
\hline 14 & I & I & 100 & / & I & / & / & 50 & $37^{\circ} \mathrm{C}, 1 \mathrm{~h}$ & - & - & - & - \\
\hline
\end{tabular}

P-P: patient's plasma; AE: patient's acid eluent; AB-P: AB-type plasma with negative antibody screening test result; PRC: piperacillin; TBT: tazobactam; RBCs: uncoated O-type red blood cells; PRC-RBCs: piperacillin-coated red blood cells; TBTRBCs: tazobactam-coated red blood cells; DAT: direct antiglobulin test; 2 days before stopping: 2 days before stopping the administration of piperacillin-tazobactam; 3 days after stopping : 3 days after stopping the administration of piperacillintazobactam.

*: The same method were used to detect drug-dependent antibodies in blood samples collected 2 days before and 3 days after the patient's stopping the administration of piperacillin-tazobactam, and the direct antiglobulin tests were used to confirm the presence of drug-dependent antibodies; $\triangle$ : Due to the presence of piperacillin in the patient's plasma before stopping the administration of piperacillin-tazobactam, the plasma reacted with both drug-coated red blood cells and uncoated red blood cells; +: strong; -: negative.

\section{Figures}



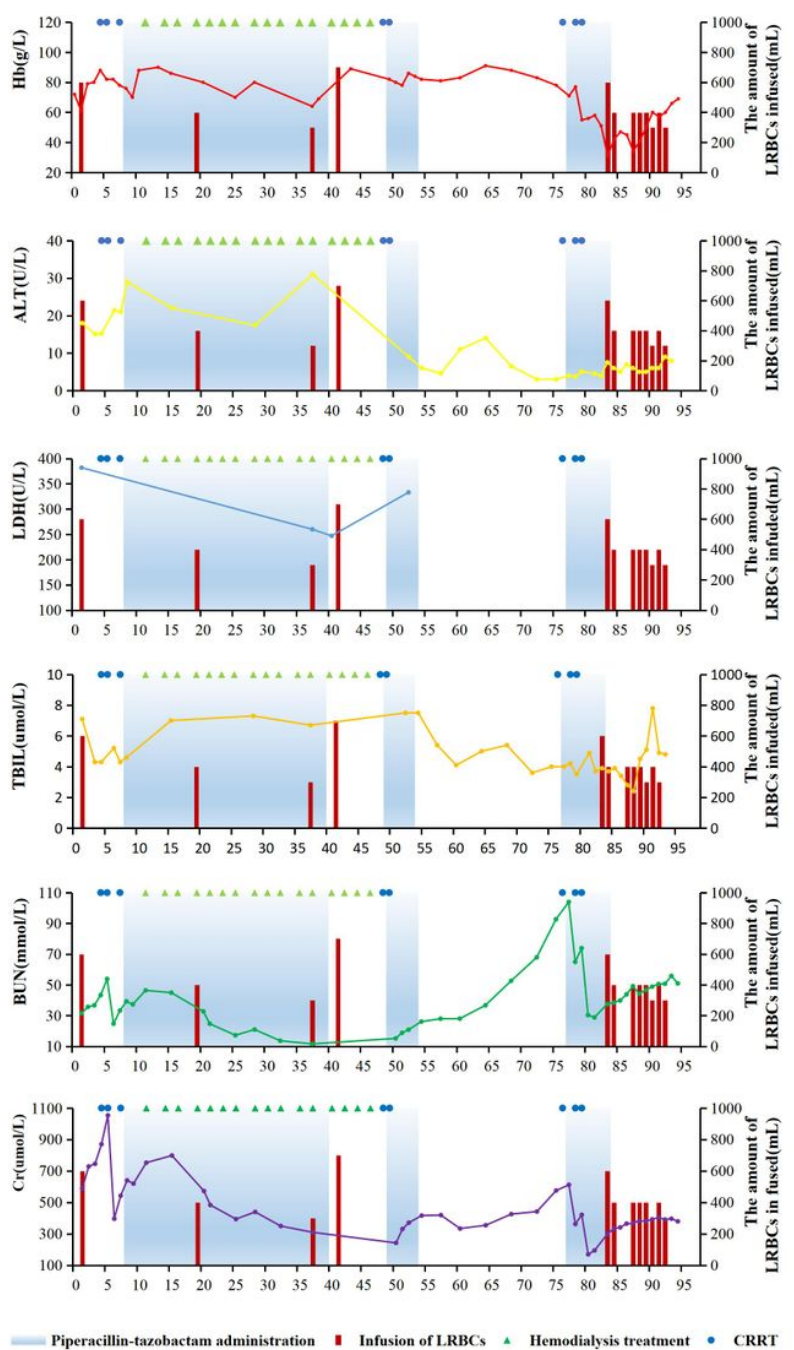

\section{Figure 1}

The dynamics of hemoglobin $(\mathrm{Hb})$, alanine transaminase (ALT), lactate dehydrogenase (LDH), total bilirubin (TBIL), blood urea nitrogen (BUN), creatinine (Cr), and piperacillin-tazobactam administration. The amount of LRBCs infused: The amount of whole blood needed to prepare leukocyte-reduced red blood cells which were infused. Since the patient's clinician in charge did not monitor the patient's lactate dehydrogenase after the second course of piperacillin-tazobactam administration, the lactate dehydrogenase data is incomplete. LRBCs: leukocyte-reduced red blood cells. CRRT: continuous renal replacement therapy. 